\title{
O papel do professor no ensino de alemão para o fim específico da leitura ${ }^{1}$
}

\section{The teacher's role in teaching German for the specific purpose of reading}

Roberta Cristina Sol Fernandes Stanke*

Universidade do Estado do Rio de Janeiro

Rio de Janeiro - Rio de Janeiro / Brasil

RESUMO: Este artigo tem por objetivo abordar o papel do professor em um curso de alemão, cujo fim específico é o desenvolvimento da habilidade de leitura nesta língua estrangeira (LE). Os resultados da pesquisa, realizada com bas eem notas de campo em um curso de alemão para leitura, diários, entrevistas, questionários, análise documental e gravaçōes em áudio e vídeo, demonstraram o papel multifacetado do professor de LE para fins específicos que, além de ensinar a língua-alvo, analisa as necessidades da situação-alvo e da situação de aprendizagem, seleciona e elabora material didático, conscientiza seu aprendiz sobre o que significa a atividade de leitura e fomenta o desenvolvimento das estratégias de leitura.

PALAVRAS-CHAVE: alemão para fins específicos, papel do professor, leitura em LE, estratégias de leitura.

ABSTRACT: This paper aims to analyze the teacher's role in a German course which has the specific purpose to develop the reading skill in this foreign language. The research was based on field notes in a German course for reading, including diaries, interviews, questionnaires, documental analysis and audio and video recordings. The results showed the multifaceted role of the foreign language teacher for specific purposes, who teaches the foreign language, analyses the needs of the target situation and of the learning situation, selects and produces didactic material, makes the learner aware of what the reading process is and foment the development of reading strategies.

KEY-WORDS: German for specific purposes, teacher's role, reading in a foreign language, reading strategies.

\footnotetext{
*roberta_stanke@yahoo.de

${ }^{1}$ Artigo baseado em minha pesquisa de mestrado orientada pela Profa. Dra. Maria José Pereira Monteiro, no âmbito do Projeto LEFE (LE para Fins Específicos) do Programa Interdisciplinar de Pós-Graduação em Linguística Aplicada da Universidade Federal do Rio de Janeiro.
} 


\section{Introdução}

O texto escrito foi por muito tempo a base das aulas de língua estrangeira (LE) durante o período do método gramática e tradução. Em meados do século 20, esse método de ensino perdeu espaço com o predomínio do método áudio-lingual. O texto escrito cedia lugar ao texto oral. No final dos anos 1970, porém, o desenvolvimento da abordagem comunicativa começou a trazer o texto escrito de volta à cena na aula de LE.

O processo ensino / aprendizagem de línguas estrangeiras para fins específicos começou a despertar, já desde os anos 1970, grande interesse em pesquisas no Brasil. Na área de alemão, a principal demanda é por cursos nos quais se desenvolva a habilidade de leitura, especialmente para fins acadêmicos.

O ensino de LE para fins específicos é, segundo Hutchinson e Waters (1987, p. 19), "uma abordagem para o ensino de línguas, na qual todas as decisōes sobre conteúdo e método são baseadas nas razões do aprendiz para a aprendizagem". ${ }^{2} \mathrm{O}$ professor de LE para fins específicos precisa levantar e analisar as necessidades da situação-alvo de uso da língua e da situação de aprendizagem, selecionar, avaliar, adaptar e até mesmo elaborar material didático, pesquisar para aperfeiçoar sua prática (HUTCHINSON; WATERS, 1987; CELANI, 1998).

Para compreender um texto escrito, conforme Koch e Elias (2006b), o leitor emprega diversas estratégias sociocognitivas. É por meio dessas estratégias, da ativação de uma série de conhecimentos armazenados na memória do leitor, que se dá o processamento textual. Afirmar, porém, que o processamento textual é estratégico, implica o pressuposto de que o leitor, na busca da compreensão, toma diversas atitudes orientadas, efetivas, eficientes, flexíveis e rápidas diante do texto (KOCH; ELIAS, 2006). Isso quer dizer que na atividade de leitura e compreensão o leitor lança mão de inúmeros subprocessos, não só de ordem inconsciente como também consciente (LEFFA, 1996).

Dessa forma, faço no presente artigo, uma revisão da literatura da área, abordando a atividade de leitura, as estratégias de aprendizagem e de leitura, o ensino de LE para fins específicos e o professor na aula de leitura. Apresento ainda o contexto de pesquisa, a sala de aula de Alemão Instrumental de uma instituição superior pública de ensino e seus atores, os instrumentos de registro

\footnotetext{
${ }^{2}$ ESP, then, is an approach to language teaching in which all decisions as to content and method are based on the learner's reasons for learning.
} 
e análise de dados, que me permitiram compreender o papel multifacetado do professor que ensina a língua alemã para o fim específico da leitura.

\section{A leitura}

A leitura é uma atividade de produção de sentidos baseada na interação autor-texto-leitor (KOCH; ELIAS, 2006b). Sendo a atividade de leitura construída nessa interação, o leitor deve levar em consideração não só os seus conhecimentos, mas também a materialidade linguística do texto. Segundo Kleiman (2004c, p. 13), a interação é um aspecto inerente ao processo de leitura ao afirmar que "é mediante a interação de diversos níveis de conhecimento, como o conhecimento linguístico, o textual, o de mundo, que o leitor consegue construir o sentido do texto" e "porque o leitor utiliza justamente diversos níveis de conhecimento que interagem entre si, a leitura é considerada um processo interativo". Sendo assim, o leitor tem um papel ativo na leitura, já que mobiliza seu conhecimento prévio para compreender um texto, inferindo significados, antecipando informaçōes e levantando hipóteses (KOCH; ELIAS, 2006). O leitor proficiente é, então, aquele que, a partir de seus objetivos de leitura, tem uma atitude estratégica e flexível ao interagir com um texto.

Pesquisas na área de leitura (KLEIMAN, 2004a, 2004b, 2004c; LEFFA, 1996; KOCH; ELIAS, 2006) demonstram que a atividade de leitura "não é um recebimento passivo de informação, mas, sim, um processo ativo, no qual o aprendiz emprega estratégias próprias de leitura e compreensão" (KRUMM, 1990, p. 20). Compreender a leitura como uma habilidade receptiva seria, então, adotar uma atitude reducionista diante dessa atividade, descrita por diversos estudiosos da área como uma atividade cognitiva complexa (KLEIMAN, 2004a, 2004b, 2004c; FULGÊNCIO; LIBERATO, 2004; LEFFA, 1996; KOCH; ELIAS, 2006), que envolve, assim como qualquer outra atividade de ordem cognitiva, fatores como percepção, processamento de informação, atenção, memória, inferência, dedução e outros. Dessa forma, Smith (1991, p. 201), afirma que

a leitura não é uma questão de identificar letras, a fim de reconhecer as palavras para que se obtenha o significado das sentenças. A identificação do significado não requer a identificação de palavras

\footnotetext{
${ }^{3}$ Verstehen ist kein passives Aufnehmen von Information, sondern ein aktiver Prozess, in dem die Lernenden eigenes Wissen, eigene Lese- und Verstehensstrategien einsetzen.
} 
individuais, exatamente como a identificação de palavras não requer a identificação de letras. Na verdade, qualquer esforço por parte de um leitor, para identificar palavras uma de cada vez, sem aproveitar a vantagem de sentido como um todo, indica um fracasso para a compreensão e está provavelmente fadado ao fracasso.

A leitura, enfim, não significa decodificar ou decifrar um código linguístico (KOCH; ELIAS, 2006; KLEIMAN 2004a, 2004b, 2004c), mas, sim uma prática social, na qual valores, crenças e vivências pessoais do leitor contribuem para a construção do sentido do texto (KLEIMAN, 2004a). Dessa forma, de acordo com Koch e Elias (2006), pode-se afirmar que a leitura é uma atividade que exige intensa participação do leitor, que, na busca pela compreensão, aplica no decorrer da atividade um modelo cognitivo, ou esquema, baseado nos conhecimentos armazenados em sua memória.

$\mathrm{Na}$ área de leitura em LE, Ehlers (1998) discute as diversas hipóteses levantadas a acerca dessa atividade: a Hipótese dos Universais de Leitura, a Hipótese da Interdependência Linguística e a Hipótese do Limiar Linguístico. De acordo com a Hipótese dos Universais de Leitura, a leitura em língua materna (LM) e em LE seriam processos idênticos e, portanto, as estratégias empregadas na leitura em LM seriam transferidas para a leitura em LE. Na Hipótese da Interdependência Linguística, as habilidades de leitura em LE dependeriam essencialmente das habilidades de leitura em LM. E na Hipótese do Limiar Linguístico, a leitura em LE dependeria do nível de proficiência na língua-alvo. Estudos mostraram, no entanto, que a leitura em LE é influenciada pelos hábitos e habilidade de leitura em LM, pelo nível de conhecimento da língua-alvo e também pelo conhecimento de mundo e textual do leitor (FARKAS, 2003).

\section{As estratégias}

As estratégias de aprendizagem, segundo Oxford (1990, p. 8), são "ações específicas do aprendiz para tornar a aprendizagem mais fácil, prazerosa, autodirigida, efetiva e transferível a novas situaçoes". ${ }^{4}$

\footnotetext{
${ }^{4}$ Learning strategies are specific actions taken by the learner to make learning easier, faster, more enjoyable, more self-directed, more effective, and more transferable to new situations.
} 
De acordo com Oxford (1990), as estratégias de aprendizagem dividemse, primeiramente, em estratégias diretas, ligadas ao processamento da línguaalvo, e indiretas, ligadas ao gerenciamento da aprendizagem. As estratégias diretas dividem-se em estratégias de memorização, cognitivas e de compreensão. As estratégias indiretas dividem-se em metacognitivas, afetivas e sociais. ${ }^{5}$

As pesquisas na área de estratégias de aprendizagem tiveram início nos anos 60 do século 20. Historicamente, os estudos das estratégias estavam ligados à Psicologia Cognitiva (O'MALLEY; CHAMOT, 1990; OXFORD, 1990), porém os rumos dessas pesquisas ultrapassaram os aspectos cognitivos e chegaram também aos aspectos de ordem interacional, contextual, afetiva e motivacional.

As estratégias de leitura, parte das estratégias de aprendizagem, são, segundo Kleiman (2004b), operações regulares para abordar um texto e dividem-se em estratégias metacognitivas, que são estratégias de ação e que podem ser controladas conscientemente, ou seja, são operaçôes realizadas com um objetivo específico; e estratégias cognitivas, que são procedimentos inconscientes de um leitor competente para compreender um texto.

De acordo com Oxford (1990), as estratégias metacognitivas proporcionam ao aluno condiçôes de coordenar o seu próprio processo de aprendizagem e ajudam-no a planejá-lo de maneira eficiente e efetiva. Tais estratégias são essenciais para uma aprendizagem bem-sucedida de línguas. Conforme Kleiman (2004c), as estratégias metacognitivas controlam e regulam o próprio conhecimento e implicam também uma reflexão sobre o próprio conhecimento, ou seja, são decisões tomadas, após uma avaliação, no intuito de se resolver uma tarefa.

É devido ao papel das estratégias metacognitivas na leitura que podemos afirmar que, (...) a leitura é um processo só, pois as diferentes maneiras de ler são apenas diversos caminhos para alcançar o objetivo pretendido (KLEIMAN, 2004c, p. 35).

Segundo Koch (2006), as estratégias cognitivas consistem em estratégias de uso do conhecimento, que facilitam e possibilitam o processamento textual. Em sentido estrito, as estratégias cognitivas "são aquelas que consistem na execução de algum 'cálculo mental' por parte dos interlocutores” (p. 50). 5 O quadro completo das estratégias de aprendizagem, de acordo com Oxford (1990,
p. 16-22), organizado por Vilaça (2003, p. 39), encontra-se no ANEXO E deste artigo. 
O uso dessas estratégias depende dos objetivos do leitor, de suas experiências - crenças, opiniões e atitudes -, do conhecimento disponível em relação ao texto e ao contexto e "torna possível, no momento da compreensão, reconstruir não somente o sentido intencional pelo produtor do texto mas também outros sentidos, não-previstos ou mesmo não desejados pelo autor" (p. 50).

Uma das características das estratégias de aprendizagem, de acordo com Oxford (1990), é a possibilidade de seu ensino. Para a autora (1990), mesmo os aprendizes mais bem-sucedidos podem melhorar o uso de suas estratégias por meio da instrução formal. O ensino de estratégias ajuda o aprendiz a usálas conscientemente e a empregá-las propriamente na resolução tarefas. Por essa razão, Oxford (1990) também afirma que as estratégias de aprendizagem podem e devem ser ensinadas. Além disso, o ensino das estratégias favorece o desenvolvimento de um aprendiz autônomo (OXFORD, 1990). Quando a autonomia do aprendiz é estimulada e praticada, este se torna mais responsável pelo seu processo de ensino, isto é, o aluno tem mais claro para si que tanto professor quanto ele próprio desempenham papéis específicos no processo ensino / aprendizagem (OXFORD, 1990).

\section{O professor e o ensino de leitura em LE}

O processo ensino / aprendizagem de LE para fins específicos, de acordo com Holmes (1981), parte do levantamento e análise das necessidades dos aprendizes, visa o desenvolvimento de habilidades e estratégias específicas para o desempenho de funçóes específicas e enfatiza o conhecimento prévio do aprendiz - de mundo e linguístico, mesmo que apenas de sua língua materna - e sua capacidade de raciocínio para a solução de tarefas.

Hutchinson e Waters (1987, p. 19) afirmam que o ensino / aprendizagem de LE para fins específicos é uma abordagem para o ensino / aprendizagem de LE, que tem como ponto de partida as necessidades do aprendiz e como fundamento a pergunta "Por que este aluno precisa aprender uma LE?". ${ }^{6}$ Respondida essa pergunta, surgirão outras sobre o próprio aprendiz - o público-alvo -, sobre o tipo de linguagem que os aprendizes terão necessidade de utilizar e sobre o contexto de aprendizagem.

No caso específico de ensino de leitura em LE, o professor precisa conhecer como se processa essa atividade, que, conforme Kleiman (2004a), é

${ }^{6}$ Why does this learner need to learn a foreign language? 
descrita como uma atividade complexa e, assim como qualquer outra tarefa cognitiva, envolverá, na mente, busca de informaçōes, aplicação de conhecimento a novas situações, engajamento da percepção, da atenção e da memória, para a compreensão textual. Fulgêncio e Liberato (2004) também descrevem a leitura como um processo complexo, no qual interagem fatores como o conhecimento linguístico, textual e de mundo, motivação e interesse. As autoras (2004, p. 13) também afirmam que "conhecer como atua cada um desses fatores é imprescindível para a discussão da prática do ensino da leitura".

O ensino de leitura consiste, de acordo com Kleiman (2004a), em sensibilizar o aprendiz com relação aos traços linguísticos do texto, em criar condiçōes na sala de aula que tornem propícia a interação via texto do aprendiz com o autor e em conscientizar esse aprendiz de que ele precisa trazer a um nível consciente todo o conhecimento prévio de que dispõe sobre o texto que lerá (p. 157). Segundo Corrêa e Cunha (2006), atividades com textos que tenham relação com assuntos e personalidades que sejam do conhecimento do aluno são importantes para o desenvolvimento da habilidade de leitura e compreensão, pois contam com a mobilização e ativação do conhecimento prévio desse aluno, que certamente formulará hipóteses e antecipará conteúdos.

A principal característica do leitor proficiente, segundo Kleiman (2004b), é a flexibilidade na leitura: ele não lança mão de apenas um procedimento, mas de vários possíveis quando um não for suficiente ou adequado para compreender o texto. $\mathrm{Na}$ busca da compreensão, o leitor proficiente também faz predições em relação ao texto, baseadas em seu conhecimento prévio (KLEIMAN, 2004b). O aprendiz-leitor, no entanto, interage inicialmente com o texto somente através de sua própria cognição, de maneira inconsciente, mas as tarefas que possibilitam imitar em sala de aula o comportamento do leitor proficiente (que tem um comportamento reflexivo e consciente) permitem ao aprendiz o desenvolvimento de estratégias necessárias para a compreensão textual. Tal "imitação (...) é um passo anterior, necessário ao desenvolvimento dessas estratégias no aluno. Tal imitação ainda constitui, se bem elaborada, um suporte temporário, a ser retirado mais tarde, para recriar o comportamento do leitor experiente" (KLEIMAN, 2004b, p. 61).

O leitor experiente também tem um objetivo ao ler um texto. Dessa forma, quando o professor elabora tarefas que deixam claro para o aprendiz os objetivos de leitura, há uma melhora significativa da capacidade de processamento e de memória por parte do leitor (KLEIMAN, 2004c). A atividade de leitura só surte efeito, para fins de desenvolvimento da compreensão leitora, a partir da determinação de objetivos para se chegar a 
propósitos específicos (KLEIMAN, 2004c). Ao se estabelecerem objetivos na leitura, o leitor recupera com mais facilidade as informações relativas aos objetivos pré-determinados (KLEIMAN, 2004c). A pré-determinação de objetivos por terceiros, ou seja, objetivos artificialmente impostos, que não proveem do próprio leitor, não é necessariamente um mal. Pelo modelo fornecido por outrem, o aluno pode começar a estabelecer seus próprios objetivos em leituras futuras, o que possibilitará também o desenvolvimento de estratégias metacognitivas adequadas para a atividade de leitura. Para Smith (1991, p. 202), "a leitura é interessante e relevante quando pode ser relacionada ao que o leitor deseja saber".?

$\mathrm{Na}$ atividade de leitura e produção do sentido, conforme Koch e Elias (2006), o leitor lança mão de várias estratégias. O ensino estratégico da leitura consiste, então, em modelar as estratégias metacognitivas e fomentar o desenvolvimento de habilidades verbais que subjazem as operaçóes inconscientes e automáticas das estratégias cognitivas (KLEIMAN, 2004b). Para Kato (1999, p. 135), "as estratégias cognitivas munem o leitor de procedimentos altamente eficazes e econômicos, responsáveis pelo processamento automático e inconsciente, enquanto as metacognitivas orientam o uso dessas estratégias para desautomatizá-las em situações de problema”.

De acordo com Melo (2006, p. 3),

quando o professor, no exercício de sua função de facilitador do processo, conscientiza seu leitor / aprendiz sobre sua atividade cognitiva automática e inconsciente e o auxilia a automatizar tais procedimentos até então utilizados inconscientemente, estará ampliando sua atividade metacognitiva voluntária e consciente, de forma a torná-lo um leitor autônomo e competente.

Kleiman (2004c) afirma que a forma do texto também determina em grande parte os objetivos de leitura. O leitor tem objetivos diferentes na leitura do caderno de economia de um jornal e na leitura da receita de um bolo, assim como o autor também tem objetivos e intenções diferentes na produção de cada tipo e forma de texto. Diante disso, é importante que o aluno tenha contato com o máximo possível de gêneros e tipos de textos diferentes. Quanto mais conhecimento textual tiver o leitor, mais fácil será a compreensão dos diversos textos (KLEIMAN, 2004c).

7 Grifo do autor. 
No ensino da leitura, Kleiman (2004a) aponta ainda a importância da exploração do título, dos subtítulos e das ilustrações em atividades pré-textuais, através das quais se podem elaborar hipóteses, ativar esquemas cognitivos e criar expectativas em relação ao conteúdo do texto, o que facilitará a leitura e produção do sentido.

O ensino da leitura consiste, então, em auxiliar o aluno a criar uma atitude de expectativa com relação ao conteúdo do texto, isto é, em mostrar ao aluno que quanto mais hipóteses forem formuladas em relação ao conteúdo, mais facilitada será a compreensão. Ensinar leitura é mostrar a importância de se autoavaliar constantemente durante o processo, ativar seus pré-conhecimentos para resolver falhas momentâneas e procurar as pistas e sinalizações textuais, pois as escolhas linguísticas do autor não são aleatórias, são aquelas que, a seu ver, melhor servem aos seus propósitos. O ensino da leitura não consiste apenas em ensinar um conjunto de estratégias, mas em ajudar a criar no aprendiz uma postura ativa para a produção do sentido, postura essa que faz da leitura uma atividade de procura da coerência e busca pela compreensão (KLEIMAN, 2004a).

\section{Pesquisando a sala de aula: registro, categorização e interpretação dos dados}

O contexto de pesquisa foi a sala de aula de Alemão Instrumental de uma instituição de ensino superior pública, durante um semestre letivo, e teve como participantes a professora da disciplina, 5 alunos, entre eles 1 graduanda em Português-Francês e mestranda do Programa de Ciência da Literatura, 1 graduanda em Desenho Industrial, 1 graduando em Música, 1 graduanda em Português-Árabe e doutoranda do Programa de Ciência da Literatura e 1 graduando em Português-Árabe e doutorando do Programa de Ciência da Literatura, e eu, observadora-participante.

Registrei os dados por meio de notas de campo e diário, transcrições das gravaçôes das aulas em áudio e vídeo, questionários, transcrições de entrevistas gravadas em áudio e vídeo e conversas informais e e-mails trocados com os participantes.

Seguindo os preceitos da ética nas pesquisas em Ciências Humanas, todos os participantes foram informados sobre a pesquisa e seus objetivos; eles autorizaram as gravações em áudio e vídeo e, para preservar suas identidades, utilizei pseudônimos para identificá-los, pois, dessa forma, os participantes da pesquisa sentem-se seguros e a dignidade humana é preservada (CELANI, 2005). 
Baseando-me teoricamente na análise de domínio de Spradley (1980) e no método de comparação de Hubbard e Power (1993) e empiricamente na observação das aulas de Alemão Instrumental, criei cinco categorias para a análise dos dados: 1) a conscientização da leitura como atividade de compreensão; 2) a importância da mobilização dos conhecimentos textual e de mundo do leitor; 3) o desenvolvimento do conhecimento linguístico do alemão; 4) o fomento e desenvolvimento das estratégias de leitura; e 5) a elaboração do material didático com base na análise de necessidades.

\section{A sala de aula de alemão para o fim específico da leitura}

Um dos primeiros passos em uma de aula de LE para o fim específico da leitura é a conscientização do aluno do que significa a atividade leitura, já que muitos aprendizes têm a ideia de que ler um texto em uma LE significa traduzi-lo, significa conhecer o significado de cada palavra nele contida. Para conscientizar seus aprendizes de que a leitura em LE é uma atividade de compreensão, e não de tradução, a professora discutiu com os alunos em sala de aula o texto "Leitura, Escrita e Tradução" (BARBOSA; CALDAS, 2002, p. 65). Segundo as autoras do texto,

(...) o processo tradutório é visto como sendo prévio à compreensão textual. O que ocorre, na verdade, é que, para se poder traduzir um texto, é preciso primeiro compreendê-lo. Isto porque a tradução se identifica, de fato, é com a produção textual. Trata-se, portanto, de uma "quinta habilidade", ou seja, uma habilidade específica a ser adquirida pelo aprendiz.

Aliada à conscientizaçăo de que a leitura em LE não ésinônimo de tradução, está também a conscientização de que a leitura em LE não é uma atividade de decodificação. Destaco, assim, um dos trechos da gravação da aula em vídeo, bem como o texto (cf. ANEXO A) selecionado pela professora para esse fim:

Professora: (...) que cê tá achando? (...) Você conseguiu ler tudo?

Bernardo: consegui.

Professora: tranquilo, né? (...) É aquela nossa proposta: você não precisa entender tudo (...). Você não precisou ler as letras certinhas. (...)

(Aula 8 - Transcrição da gravação em vídeo)

Com esse tipo de atividade, a professora conscientiza seus alunos, conforme Smith (1991), de que a leitura não é uma mera identificação de letras 
e reconhecimento palavras para se obter o significado de sentenças. A professora levou seus alunos a perceber que a compreensão do texto escrito está ligada à construção do sentido do texto como um todo.

Além de conscientizar o aprendiz de que a leitura é uma atividade de compreensão, o professor de LE para fins específicos precisa conscientizá-lo de seu papel ativo na busca da construção do sentido do texto. Esse foi outro momento que se verificou na observação das aulas de Alemão Instrumental. Tal papel ativo é exercido por meio da mobilização de seus conhecimentos prévios, principalmente dos conhecimentos textual e de mundo, pois, no início de um curso de LE para leitura, o aluno dispóe de nenhum, ou quase nenhum, conhecimento linguístico (KOCH; ELIAS, 2006). Para trabalhar a importância da mobilização dos conhecimentos textual e de mundo na atividade de leitura, a professora selecionou um texto publicitário da companhia aérea Lufthansa (cf. ANEXO B). Destaco, a seguir, trecho da transcrição da gravação em vídeo da aula, na qual se abordou este aspecto:

Professora: (...) Bernardo, o que que cê acha que é isso aqui?

Bernardo: (hesitante)

Professora: é título de livro, como a gente já tinha visto nos outros, Bernardo?

Bernardo: não. (...) Pode ser... jornal e revista?

Professora: jornal e revista, tá certo, a fonte, né? (...) E este texto tem o objetivo de fazer o quê? (...) Comunicar o quê?

Bernardo: é algum cartaz, então?

Professora: pode ser.... Diga, Joana.

Joana: um anúncio.

Professora: (...) e está anunciando o quê?

Joana: anúncio da Lufthansa.

Professora: (...) que é a Lufthansa, Bernardo?

Bernardo: eu não sei o que que é. (...)

(Aula 7 - Transcrição da gravação em vídeo)

Como se pode observar, a falta de conhecimento de mundo e textual de Bernardo não lhe permitiu levantar a hipótese de que se tratava de uma propaganda publicitária da companhia aérea alemã Lufthansa, o que não ocorreu do mesmo modo com Joana. A professora dá continuidade à atividade com o referido texto, explorando a área de conhecimento de Bernardo, a Música.

Professora: (...) esse é o nosso anúncio da Lufthansa e a Lufthansa é uma companhia aérea alemã, e o texto aí em cima tem algumas coisas próprias da Alemanha. Por exemplo, Bernardo, que que tem ali que você reconhece que é específico da Alemanha? 
Bernardo: Deutschland.

Professora: Deutschland que é a palavra em alemão para Alemanha. Que mais? Bernardo: (hesitante)

Professora: aí pelo menos um você conhece.

Bernardo: (hesitante) eu não sei se é isso, não.

Professora: eu vou ler: (Professora lê o texto da folha 13 em voz alta). Qual éa palavra que você reconheceu aí, Bernardo?

Bernardo: Bach?

Professora: pronto! E então? Sua área! (...)

(Aula 7 - Transcrição da gravação em vídeo)

O fato de a professora ter lido o texto em voz alta demonstra a sua sensibilidade e experiência, pois sabendo que Bernardo era da área de Música, e estava acostumando a cantar em alemão, a professora acreditava que a sonoridade das palavras talvez pudesse ajudá-lo, o que realmente teve um resultado positivo, já que o aluno percebeu e compreendeu o nome do compositor Bach. Dessa forma, a professora não só aproximou a atividade da realidade do aluno como também lhe demonstrou a importância de fazer uso de seu conhecimento prévio para a leitura de um texto escrito em LE. Essa prática da professora vai ao encontro do que Kleiman (2004c, p. 20) afirma sobre a importância da mobilização do conhecimento prévio: "aquela parte do nosso conhecimento de mundo que é relevante para a leitura do texto deve estar ativada, isto é, deve estar num nível consciente, e não perdida no fundo de nossa memória”. Além disso, contata-se que

na aula de leitura é possível criar condições para o aluno fazer predições, orientado pelo professor, que além de permitir-lhe utilizar seu próprio conhecimento, supre eventuais problemas de leitura do aluno, construindo suportes para o enriquecimento dessas predições e mobilizando seu maior conhecimento sobre o assunto (KLEIMAN, 2004b, p. 52).

A professora instruiu seus alunos também sobre a importância dos elementos que fazem parte de um texto e que devem ser observados na leitura, como o título, por exemplo, que é um "elemento constitutivo do texto cuja função é, geralmente, chamar a atenção do leitor e orientá-lo na produção de sentido" (KOCH; ELIAS, 2006, p. 13). É com base no título que o leitor levanta as primeiras hipóteses em relação ao tema ou assunto do texto (KLEIMAN, 2004c, p. 59). “Com 'previsões' motivadas pelo título, 'adentramos' o texto, prosseguindo em nossa atividade de leitura e produção 
de sentido" (KOCH; ELIAS, 2006, p. 14). Em uma das aulas, a professora alertou os alunos a prestar atenção nos elementos constitutivos do texto: "(...) O título traz muitas pistas sobre o texto. Por que algo está em negrito ou em itálico em um texto? Isso pode ser uma pista" (Aula 2 - Diário da observadora).

Além de instruir os aprendizes sobre a importância de engajar seus conhecimentos textual e de mundo para a leitura, outro momento de fundamental importância observado nas aulas de alemão para leitura é o desenvolvimento do conhecimento linguístico, pois, conforme Kleiman (2004c), o conhecimento linguístico desempenha papel central no processamento textual e abrange o conhecimento sobre a pronúncia, o vocabulário, as regras e o uso da língua.

A grande maioria dos aprendizes que ingressa no curso de alemão para leitura, ou Alemão Instrumental, não possui conhecimento prévio da línguaalvo, aliás, nenhum conhecimento prévio da língua alemã é pré-requisito para frequentar o curso de Alemão Instrumental da instituição de ensino pesquisada. O desenvolvimento desse conhecimento ocorre, então, paulatinamente, conforme afirmou a professora da disciplina: "Começa-se com estruturas simples - frases, oraçōes - não com um texto longo" (Aula 2 - Diário da observadora).

Em um curso de LE para o fim específico da leitura, os alunos adquirem um conhecimento sistêmico da língua que lhes permite compreender textos escritos em alemão. A gramática é uma ferramenta a serviço da compreensão leitora. Primeiramente são sistematizadas as estruturas gramaticais que são indispensáveis para tornar produtivo o ato de ler e compreender textos em língua alemã. Em seguida, a sistematização das estruturas da língua alemã é intensificada, para que o aluno seja capaz de interagir, progressivamente, com textos mais complexos.

O primeiro contato com a língua alemã dá-se por meio de títulos de livros, depois os índices são trabalhados, em seguida, nomes de disciplinas e ementas de cursos universitários, verbetes de enciclopédias, até chegar a textos completos ao final do curso (MONTEIRO; MELO, 2003). E é com base nos textos escritos com os quais os aprendizes interagem que as estruturas gramaticais vão sendo sistematizadas.

Mais um passo na aula de alemão para o fim específico da leitura, além do ensino da língua alvo, baseado em uma progressão gramatical a serviço da leitura e compreensão do texto escrito, é o fomento do desenvolvimento de estratégias de leitura. De acordo com Kleiman (2004b, p. 50), "o ensino 
estratégico de leitura consistiria, por um lado, na modelagem das estratégias metacognitivas, e, por outro, no desenvolvimento de habilidades verbais subjacentes aos automatismos das estratégias cognitivas".

Ao iniciar o fomento e desenvolvimento das estratégias cognitiva e metacognitiva de leitura, a professora explicou aos alunos o que são estratégias, como se dividem, como funcionam e qual a sua importância para a aula de leitura. Ao informar aos alunos sobre as estratégias cognitivas e metacognitiva de leitura, a professora mostrava a eles de que maneira tais estratégias seriam fomentadas na sala de aula e, principalmente, como o emprego e desenvolvimento dessas estratégias lhes auxiliaria no desenvolvimento da habilidade de leitura em alemão. Conforme Oxford (1990), um dos passos para o ensino das estratégias é que o processo seja conduzido de maneira completamente informada, isto é, o professor deve mostrar aos alunos, da forma mais completa possível, a importância das estratégias e sua possível transferência a novas situações.

Uma das primeiras estratégias de leitura trabalhadas em sala de aula foi a estratégia cognitiva analisando contrastivamente, com base em um texto que fora distribuído aos alunos em sala de aula (cf. ANEXO C). Os alunos deveriam associar os títulos em alemão à esquerda com os títulos correspondentes em inglês à direita. A transcrição do trecho da aula na qual essa atividade foi desenvolvida ilustra esse trabalho:

Professora: porque vocês tiveram tanta facilidade?

Gisele: por causa da semelhança.

Daniel: são parecidos.

Professora: por causa da semelhança dos textos. Joana, alguma dificuldade com algum? Algum que cê demorou um pouquinho mais?

Joana: o último.

Professora: em inglês ou em alemão?

Joana: em alemão.

Professora: (...) Como você chegou à conclusão que o 13 era o f?

Joana: por causa do Sommer que parece com Summer.

Professora: é por aí mesmo. (...) Em outra turma alguém não conseguiu compreender algum título, aí quando eu perguntei como ele tinha resolvido isso, ele disse "foi a única que sobrou". Aparentemente parece uma estratégia boba, mas é uma estratégia. Ele olhou, comparou e concluiu: "foi a que sobrou". Isso também é uma estratégia, tá?

(Aula 5 - Transcrição da gravação em vídeo)

Nessa atividade, observa-se que a professora incentivava os alunos com perguntas a verbalizar o caminho mental que percorreram até chegarem a suas 
respostas. Tal fato evidencia o ensino estratégico da leitura (KLEIMAN, 2004b). A professora conscientiza seus alunos de sua atividade cognitiva automática e inconsciente, fazendo com que os procedimentos que eram até então inconscientes tornem-se conscientes. Isso faz com que a atividade metacognitiva do aprendiz seja ampliada e contribui para torná-lo um leitor autônomo e competente (MELO, 2006).

Com essa atividade, a professora aproveitou também para fomentar a estratégia usando outras pistas, quando ela relatou que, em outra turma, um aluno disse que achou o título em alemão corresponde ao título em inglês, porque aquele título em alemão foi o que sobrara. De acordo com a classificação de Oxford (1990), a estratégia usando outras pistas não é uma estratégia cognitiva, nem metacognitiva, mas uma estratégia de compensação, pertencente ao complexo adivinhando inteligentemente.

Outra estratégia fomentada em sala de aula foi a estratégia cognitiva destacando. O texto selecionado pela professora foi um artigo do jornal alemão online Die Welt (cf. ANEXO D). Ao entregá-lo aos alunos, a professora deu a seguinte informação:

Professora: cê vai ler o texto e ao ler o texto você já vai fazendo algumas marquinhas. (...) Cê vai assinalar da forma como você quiser: circulando, sublinhando, com marca-texto (...).

(Aula 13 - Transcrição da gravação em vídeo)

A estratégia cognitiva destacando, empregada no momento da leitura, auxiliou a aluna a empregar, após a leitura do texto, a estratégia metacognitiva formulando hipóteses, fomentada pela professora, como se verifica no trecho da transcrição da gravação da aula em vídeo abaixo:

Professora: (...) com base no que você assinalou, (...) do que trata o texto?

Renata: (...) de um grupo (...) que fez um protesto.

Professora: (...) e por que você acha que é um grupo?

Renata: porque tem na foto. (risos)

Professora: (...) exatamente. A foto (...) demonstra que é um grupo, e é gente protestando, né?

(Aula 16 - Transcrição da gravação em vídeo)

Além das estratégias citadas acima, a aluna empregou a estratégia cognitiva raciocinando dedutivamente, pois, não só os elementos textuais que a aluna marcara durante a leitura ajudaram-na a levantar a hipótese de que o texto tratava-se de pessoas protestando como também a foto que acompanhava 
o artigo jornalístico. Deve-se também observar que a atitude estratégica da aluna é ratificada pela professora.

Em outro momento da aula, observou-se também que, ao interagir com a propaganda publicitária da companhia aérea alemã Lufthansa (cf. ANEXO B), a aluna Joana empregou não só a estratégia cognitiva analisando expressóes como também a estratégia cognitiva analisando contrastivamente, para chegar ao significado da palavra Fluggesellschaft. A aluna utilizou as referidas estratégias e seu conhecimento da língua inglesa, para decompor a palavra e percebeu que o substantivo Flug, em alemão, tinha semelhança com o verbo $f l y$, em inglês. Isso quer dizer que o trabalho de desautomatização dos processos inconscientes dos aprendizes, fomentado pela professora, ajudou Joana a empregar, nesse momento, de forma consciente, tais estratégias, conforme trecho da sétima aula, transcrito abaixo:

Professora: (...) Bom, então veja bem, a gente tem a Alemanha, né, que é, digamos, que é um conceito guarda-chuva, o conceito macro, né? E debaixo dela nós temos o Beckenbauer, tá? O rio Reno, o Goethe e o palavrão aí embaixo. Esse palavrão poderia ser o quê, considerando que isso aqui é uma propaganda da Lufthansa? O que poderia ser Fluggesellschaft?

Joana: linhas aéreas.

Professora: linhas aéreas. Companhia aérea. Fluggesellschaft significa companhia aérea. (...)

Joana: Flug também parece $f l y$.

Professora: isso. O verbo éfliegen e o substantivo que é Flug, que lembra o inglês, tá? (Aula 7 - Transcrição da gravação em vídeo)

De acordo com Kleiman (2004b), uma das características do leitor proficiente é ter um objetivo para leitura. Tal característica faz da leitura uma atividade consciente, reflexiva e intencional. Assim, foi fomentada a estratégia metacognitiva estabelecendo metas e objetivos. Em todos os exercícios propostos, que envolviam compreensão textual, a professora formulava perguntas que deveriam ser lidas antes do texto. Antes de cada tarefa, a professora relembrava aos alunos a postura que deveriam adotar:

Professora: (...). Qual é a primeira coisa que você vai fazer, Bernardo?

Bernardo: ler a [parte] de baixo.

Professora: e por quê? Deixa eu explicar pra você porquê. Quando você recebe, quando eu dou pra vocês um trabalho, uma tarefa, uma atividade, a primeira coisa que se deve fazer é ler as perguntas. Certo? Por quê? Nossa situação de leitura aqui é uma situação totalmente artificial. Eu procuro tornar essa situação 
artificial de leitura tão próxima da realidade quanto possível. Numa situação real de leitura, o que que aconteceria, como é que seria? (...) Na biblioteca ou em casa, você vai se interessar por um determinado livro ou por uma determinada revista. Como? Por quê? O que vai te levar, o que levou você a ter o interesse despertado pelo livro? Você olhou o livro e te chamou a atenção alguma coisa. Por exemplo, a palavra Bach. Bach é um compositor, da área de música. Te chamou a atenção a palavra Piano. Te chamou a atenção a palavra Stimme, que é voz (...).

(Aula 8 -Transcrição da gravação em vídeo)

Verifica-se que a professora procurava mostrar aos alunos que ter um objetivo é fundamental para a leitura. De acordo com Kleiman (2004b), o professor precisa mostrar para o aluno a importância de ler com um objetivo e agir de forma a suprir a ausência de objetivos definidos pelo próprio leitor. No caso de Bernardo, da área de Música, se o seu objetivo fosse fazer, por exemplo, uma pesquisa sobre Bach, o nome do compositor em um livro ou revista despertaria o seu interesse. $\mathrm{Na}$ sala de aula, portanto, as perguntas que eram lidas antes dos textos faziam o papel do interesse do leitor de acordo com seus objetivos.

Além de fomentar a estratégia estabelecendo metas e objetivos, a professora fomentou a estratégia cognitiva apreendendo a idéia rapidamente ou, conforme a nomenclatura de Brown (2001), skimming e scanning. A professora mostrou que, considerando seu objetivo, o aluno pode passar rapidamente os olhos (skimming) nas diferentes obras disponíveis, selecionar aquilo que possa interessar-lhe e procurar a informação que deseja (scanning).

Nessa mesma atividade, percebe-se que a professora seguiu um dos passos para o ensino das estratégias, conforme propõe Oxford (1990, p. 207): "considerar aspectos motivacionais". A professora não só explicou o funcionamento da estratégia como também a exemplificou com base na área de interesse do aluno Bernardo.

De acordo com Kleiman (2004c, p. 35), "os objetivos são também importantes para outro aspecto da atividade do leitor que contribui para a compreensão: a formulação de hipóteses". Tal aspecto é enfatizado pela professora nas aulas:

Professora: (...) a gente vai tá sempre trabalhando com levantamento de hipóteses. Então a gente levanta todas as hipóteses, a gente checa, então, no texto, se a hipótese que a gente levantou bate, se confirma.

(Aula 9-Transcrição da gravação em vídeo) 
Outras tarefas do professor de LE para fins específicos também observada durante as aulas de Alemão Instrumental que foram acompanhadas são, com base na análise das necessidades de uso e da situação de aprendizagem da LE, selecionar, avaliar, adaptar e até mesmo elaborar material didático (HUTCHINSON; WATERS, 1987; CELANI, 1998). Para ilustrar esse trabalho da professora, destaco o seguinte trecho de uma entrevista feita com ela:

Costumo conversar (...) com os alunos no primeiro dia de aula e peço-lhes que respondam um questionário. $\mathrm{O}$ diálogo e as respostas do questionário me permitem detectar quais são suas necessidades, e a partir disto elaboro um material didático que venha ao encontro de suas necessidades e de seus interesses. Os critérios para a seleção dos textos - sempre autênticos - levam em consideração sua adequação, ao nível já alcançado pelo aprendiz bem como sua capacidade de despertar interesse, tanto pela temática quanto pela atualidade do texto.

(Transcriçāo da entrevista com a professora)

Observa-se que a professora da disciplina faz uma análise criteriosa da situação-alvo, da situação de aprendizagem, levando em conta as necessidades de seus aprendizes para elaborar um material didático adequado, já que, segundo Hutchinson e Waters (1987, p. 96), avaliar e escolher um material didático "é uma questão de julgamento da adequação de algo para um propósito específico", ${ }^{8}$ ou seja, "é basicamente um processo de combinação: combinar necessidades com soluçōes disponíveis”" (p. 97).

\section{Considerações finais}

Em um curso de alemão cujo fim específico é a compreensão de textos escritos nesta LE, pode-se constatar o papel multifacetado do professor, descrito por estudiosos da área como facilitador, ajudante, conselheiro, coordenador, designer do curso, fornecedor de material didático, pesquisador, colaborador e avaliador (DUDLEY-EVANS; ST. JOHN, 1998).

O primeiro passo observado nas aulas diz respeito ao trabalho de conscientização feito pela professora com os aprendizes sobre o que significa a atividade de leitura. Os alunos percebem que seu papel não é apenas o de decodificar o que está escrito, palavra por palavra, e voltam seu olhar para o todo.

\footnotetext{
${ }^{8}$ Evaluation is a matter of judging the fitness of something for a particular purpose.

${ }^{9}$ Evaluation is basically a matching process: matching needs to available solutions.
} 
O segundo passo refere-se à conscientização do aprendiz da importância da mobilização de seus conhecimentos textual e de mundo, para a construção do sentido do texto. Dessa forma, os alunos compreendem que devem ter um papel ativo na sua interação com os textos.

O terceiro passo relaciona-se ao desenvolvimento do conhecimento linguístico em alemão, que se dá gradativamente e baseia-se apenas em estruturas gramaticais que são fundamentais para a compreensão de textos escritos.

Em um quarto momento, observou-se o fomento e desenvolvimento das estratégias de leitura. Conhecendo uma gama de estratégias, o leitor tem a possibilidade de desenvolver uma das principais características do leitor proficiente: a flexibilidade na leitura (KLEIMAN, 2004b).

$\mathrm{O}$ quinto momento está ligado à elaboração do material didático, considerando o levantamento e da análise de necessidades da situação-alvo e da situação de aprendizagem. Todo o material atendia às necessidades identificadas e era coerente com a proposta do curso, pois estava voltado para o desenvolvimento da habilidade de leitura em alemão.

É importante destacar ainda que a professora da disciplina que acompanhei fomentava, além das estratégias cognitivas e metacognitivas de leitura, estratégias de compensação, de memória, sociais e afetivas, demonstrando, dessa forma, que ela via seus alunos não só como seres cognitivos mas também como seres sociais e afetivos. Vale destacar também que, ao fomentar o desenvolvimento de estratégias de leitura, o professor favorece a autonomia do aprendiz. Aprendizes mais autônomos são mais motivados, responsabilizamse por seu processo de ensino / aprendizagem e têm, assim, um papel ativo nesse processo (OXFORD, 1990).

\section{Referências}

BARBOSA, Heloísa G.; CALDAS, Beatriz F. Leitura, Escrita e Tradução. Cadernos de Letras, Rio de Janeiro, v. 18, p. 65-73, 2002.

BROWN, H. Douglas. Teaching by Principles. An Interactive Approach to Language Pedagogy. New Jersey: Englewood Cliffs. Prentice Hall Regents, 2001. 480p.

CELANI, M. A. A. Questões de ética na pesquisa em Lingüística Aplicada. Linguagem \& Ensino, v. 8, n. 1, p. 101-122, 2005. 
CELANI, M. A. A. A Retrospective View of an ESP Teacher Education Programme. The ESPecialist, São Paulo, v. 19, n. 2, p. 233-244, 1998. Disponível em: <http://www2.lael.pucsp.br/especialist/192celani.ps.pdf>. Acesso em: 3 jan. 2007.

CORRÊA, A. M. S.; CUNHA, T. R. Trabalhando a leitura em sala de aula. In: PAULIUKONIS, M. A. L.; SANTOS, L. W dos (Org.). Estratégias de leitura: texto e ensino. Rio de Janeiro: Lucerna, 2006. p. 81-91.

DUDLEY-EVANS, Tony; ST. JOHN, Maggie Jo. Developments in English for Specific Purposes. Cambridge: Cambridge University Press, 1998. 301p.

EHLERS, Swantje. Lesetheorie und fremdsprachliche Lesepraxis aus der Perspective des Deutschen als Fremdsprache. Tübingen: Gunter Narr Verlag, 1998. 320p.

FARKAS, O. Lesen in der Fremdsprache: Ein Zusammenspiel unterschiedlicher Performanzfaktoren. Eine empirische Untersuchung anhand von Protokollen Lauten Denkens. In: DIEKMANNSHEMKE, H. (Hg). Zeitschrift für angewandte Linguistik (ZfAL)39/2003, 29-51. Disponível em: <http://www.uni-koblenz. de/-diekmann/zfal/zfalarchiv/zfal39_2.pdf>. Acesso em: 18 jun. 2007.

FULGÊNCIO, Lúcia; LIBERATO, Yara. Como facilitar a leitura. 8. ed. São Paulo: Contexto, 2004. 99p.

HOLMES, John. What do we mean by ESP? Projeto Ensino de Inglês Instrumental em universidades Brasileiras. Working papers, n. 2. São Paulo: PUC São Paulo, 1981. 33p. Disponível em: <http://www.pucsp.br/pos/lael/cepril/ workingpapers/wp02.PDF>. Acesso em: 10 jan. 2007.

HUBBARD, R. S.; POWER, B. M. Pentimento: strategies for data analysis. In: The Act of Classroom Inquiry, 1993.

HUTCHINSON, T.; WATERS, A. English for Specific Purposes. A learningcentred Approach. Cambridge: Cambridge University Press, 1987. 183p.

KATO, Mary. O aprendizado da leitura. 5. ed. São Paulo: Martins Fontes, 1999. 122 .

KLEIMAN, Angela. Leitura: ensino e pesquisa. 2. ed. Campinas: Pontes, $2004 a$. $213 p$.

KLEIMAN, Angela. Oficina de leitura: teoria e prática. 10. ed. Campinas: Pontes, 2004b. 102p.

KLEIMAN, Angela. Texto e leitor: aspectos cognitivos da leitura. 9. ed. Campinas: Pontes, 2004c. 82p.

KOCH, Ingedore. Desvendando os segredos do texto. 5. ed. São Paulo: Cortez, 2006. 168p. 
KOCH, Ingedore V.; ELIAS, Vanda Maria. Ler e compreender: os sentidos do texto. São Paulo: Contexto, 2006. 216p.

KRUMM, Hans-Jürgen. Vom Lesen fremder Texte. Textarbeit zwischen Lesen und Schreiben. Fremdsprache Deutsch, München, H. 2, p. 20-23, 1990.

LEFFA, V. J. Fatores da Compreensão na Leitura. Cadernos do IL, Porto Alegre, v.15, n.15, p.143-159, 1996. Disponível em: <http://www.leffa.pro.br/ fatores.htm>. Acesso em: 6 jan. 2007.

MELO, Sílvia D. B. de. Estratégias de leitura de textos acadêmicos: um relato de experiência. In: VI. Brasilianischer Deutschlehrerkongress/I. Lateinamerikanischer Deutschlehrerkongress/2. Lateinamerikanisches Delegiertentreffen des IDV, 2006, São Paulo. Anais: VI. Brasilianischer Deutschlehrerkongress/I. Lateinamerikanischer Deutschlehrerkongress/2. Lateinamerikanisches Delegiertentreffen des IDV. São Paulo: ABrAPA, 2006, p. 1-6. Disponível em: <http://www.abrapa.org.br/cd/pdfs/Melo-S12-Silviade.pdf>. Acesso em: $1 \mathrm{fev}$. 2011.

MONTEIRO, Maria José P.; MELO, Sílvia B. de. A Língua Alemã para Fins Específicos na Faculdade de Letras da UFRJ. Cadernos de Letras, Rio de Janeiro, v. 20, p. 145-152, 2003.

O'MALLEY, J.; CHAMOT, A. Learnig Strategies in Second Language Acquisition. Cambridge: Cambridge University Press, 1990. 260p.

OXFORD, Rebecca L. Language Learning Strategies: What Every Teacher Should Know. New York: Newbury House, 1990. 342p.

SMITH, F. Compreendendo a leitura: uma análise psicolingüística da leitura e do aprender a ler. 3 ed. Porto Alegre: Artes Médicas, 1991. 428p.

SPRADLEY, J. P. Participant Observation. New York: Holt, Rinehart \& Winston, 1980. 195p.

VILAÇA, M. L. C. Estratégias na aprendizagem de língua estrangeira: um estudo de caso autobiográfico. 2003. 158 f. Dissertação (Mestrado em Interdisciplinar de Linguística Aplicada) - Faculdade de Letras, Universidade Federal do Rio de Janeiro, Rio de Janeiro, 2003. 


\section{Anexos}

\section{Anexo A}

\section{UNIVERSIDADE \\ Faculdade \\ Departamento \\ / Setor \\ ALEMÃO INSTRUMENTAL}

Vejam como é interessante nosso cérebro:

De aorcdo com uma pqsieusa de uma uinrvesriddae ignlsea, não ipomtra em qaul odrem as lrteas de uma plravaa etãso, a úncia csioa iprotmatne é que a piremria e útmlia liteas etejasm no lgaur crteo $O$ rseto pdoe ser uma bçguana ttaol que vcoê pdoe anida ler sem pobrlmea. Itso é poqrue nós não lmeos cdaa lrtea isladoa, mas a plravaa cmoo um tdoo.

Sohw de bloa!

\section{Anexo B}

Deutschland

hat nur einen Beckenbauer,

nur einen Bach,

nur einen Rhein,

nur einen Goethe

und nur eine Fluggesellschaft.

\section{Lufthansa}




\section{Anexo C}

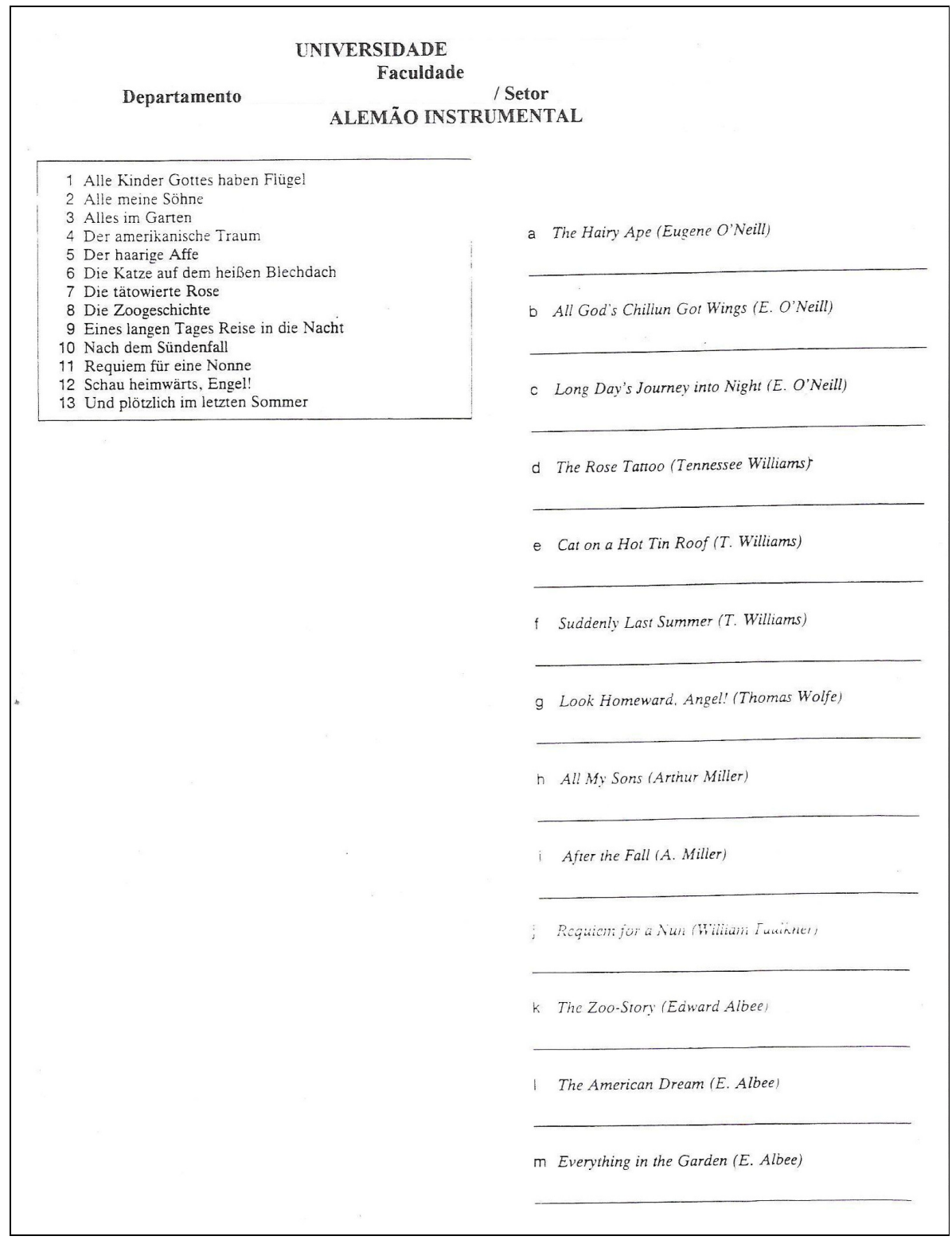




\section{Anexo D}

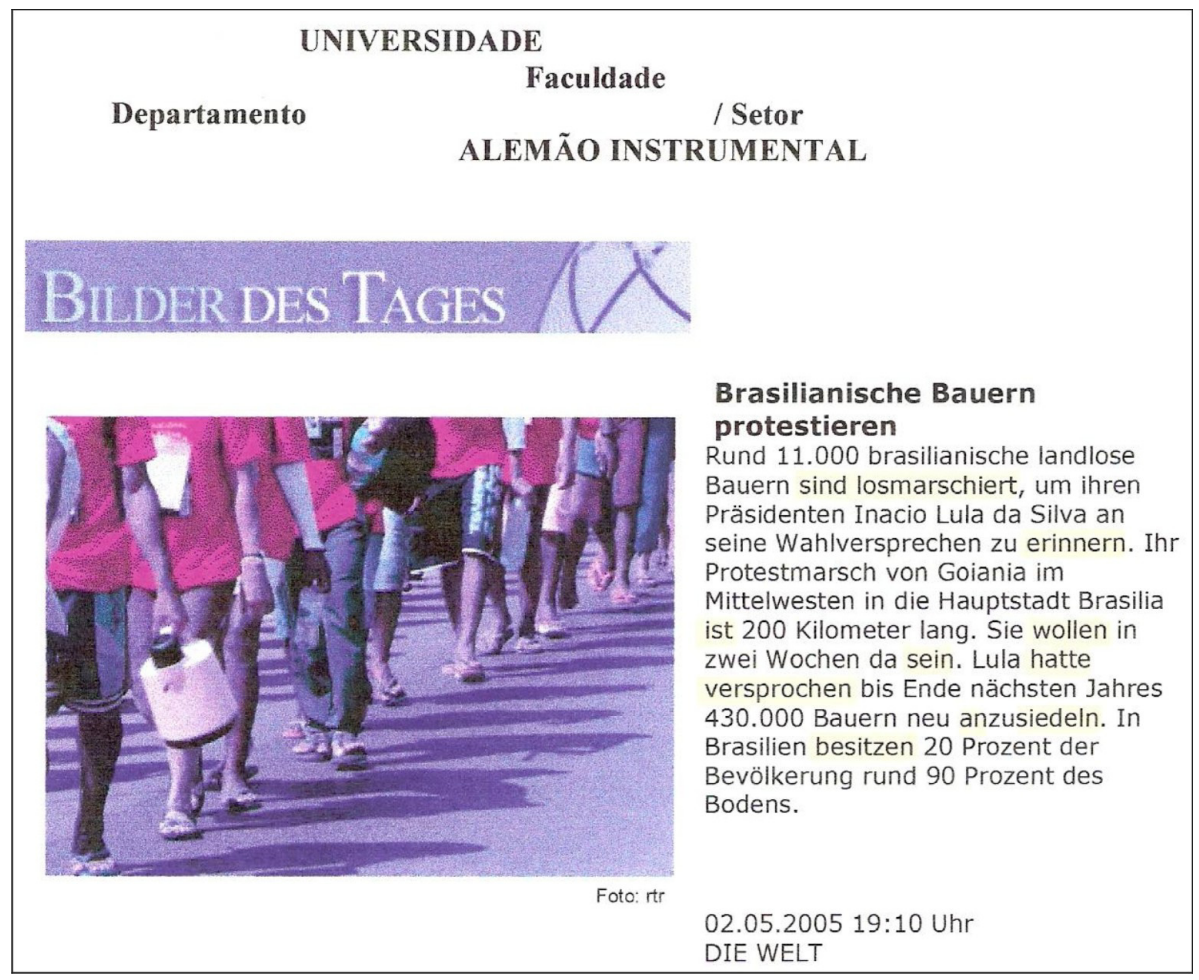

Usando pistas linguísticas 


\section{Anexo E}

Inventário completo das estratégias de Oxford (1990: 16-22)

\section{Estratégias diretas:}

\section{Estratégias de memória}

$>$ Criando ligações mentais

$\checkmark$ Agrupando

$\checkmark$ Associando/elaborando

$\checkmark$ Inserindo palavras novas num contexto

$>\quad$ Aplicando imagens e sons

$\checkmark$ Usando imagens

$\checkmark$ Fazendo mapeamento semântico

$\checkmark$ Usando palavras-chaves

$\checkmark$ Representando sons na memória

\section{Revisandobem}

$\checkmark$ Fazendo revisão estruturada

\section{Empregando ação}

$\checkmark$ Usando resposta ou sensação física

$\checkmark$ Usando técnicas mecânicas

\section{Estratégias cognitivas}

\section{$>$ Praticando}

$\checkmark$ Repetindo

$\checkmark$ Praticando com sons e sistemas escritos

$\checkmark$ Reconhecendo e usando fórmulas e padrões

$\checkmark$ Recombinando

$\checkmark$ Praticando naturalmente

$>\quad$ Recebendo e enviando mensagens

$\checkmark$ Apreendendo a ideia rapidamente

$\checkmark$ Usando recursos para enviar e receber mensagens Analisando e raciocinando

$\checkmark$ Raciocinando dedutivamente

$\checkmark$ Analisando expressões

$\checkmark$ Analisando contrastivamente (entre línguas)

$\checkmark$ Traduzindo

$\checkmark$ Transferindo

$>$ Criando estruturas para recepção e produção

$\checkmark$ Tomando notas

$\checkmark$ Resumindo

$\checkmark$ Destacando 


\section{Estratégias compensação}

\section{Adivinhando inteligentemente}

$\checkmark$ Usando pistas linguísticas

$\checkmark$ Usando outras pistas

\section{Superando limitações na fala e na escrita}

$\checkmark$ Alternando para a língua materna

$\checkmark$ Obtendo ajuda

$\checkmark$ Usando mímicas ou gestos

$\checkmark$ Evitando comunicação total ou parcialmente

$\checkmark$ Selecionando o tópico

$\checkmark$ Ajustando ou aproximando a mensagem

$\checkmark$ Moldando palavras

$\checkmark$ Usando circunlóquio ou sinônimos

\section{Estratégias indiretas:}

\section{Estratégias metacognitivas}

\section{$>$ Centralizando sua aprendizagem}

$\checkmark$ Revendo e relacionando com o material já conhecido

$\checkmark$ Prestando atenção

$\checkmark$ Adiando produção oral para focalizar na percepção oral

\section{$>\quad$ Organizando e planejando sua aprendizagem}

$\checkmark$ Fazendo descobertas sobre a aprendizagem de línguas

$\checkmark$ Organizando

$\checkmark$ Estabelecendo metas e objetivos

$\checkmark$ Identificando o propósito da tarefa

$\checkmark$ Planejando para uma tarefa linguística

(ouvindo, lendo, falando, escrevendo com um propósito)

$\checkmark$ Buscando oportunidades para prática

\section{Avaliando a sua aprendizagem}

$\checkmark$ Automonitorando

$\checkmark$ Autoavaliando

\section{Estratégias afetivas}

$>$ Reduzindo sua ansiedade

$\checkmark$ Usando relaxamento progressivo, respirando profunda, ou meditação

$\checkmark$ Usando música

$\checkmark$ Usando risos 
$>\quad$ Encorajando a si próprio

$\checkmark$ Fazendo declarações positivas

$\checkmark$ Arriscando-se sensatamente

$\checkmark$ Recompensando-se

$>\quad$ Medindo sua temperatura emocional

$\checkmark$ Ouvindo o seu corpo

$\checkmark$ Usando um checklist

$\checkmark$ Escrevendo um diário de aprendizagem da língua

$\checkmark$ Discutindo os seus sentimentos com alguém

\section{Estratégias sociais}

\section{$>\quad$ Fazendo perguntas}

$\checkmark$ Solicitando esclarecimentos ou verificação

$\checkmark$ Solicitando correções

$>\quad$ Cooperando com outros

$\checkmark$ Cooperando com pares

$\checkmark$ Cooperando com usuários proficientes da nova língua

$>\quad$ Criando empatia com outros

$\checkmark \quad$ Desenvolvendo a compreensão cultural

$\checkmark \quad$ Conscientizando-se dos sentimentos e emoções dos outros

Recebido em 28/2/2011. Aprovado em 12/10/2011. 